\title{
Toxicidade da samambaia (Pteridium aquilinum (L.) Kuhn) \\ para a saúde animal e humana
}

\section{Role of bracken fern (Pteridium aquilinum (L.) Kuhn) in animal and human heath}

\author{
Guilherme Durante Cruz ${ }^{1}$, Ana Paula F. R. L. Bracarense ${ }^{2 *}$
}

\section{Resumo}

O artigo revisa algumas das principais características da planta Pteridium aquilinum (samambaia) bem como as conseqüências da sua ingestão por animais de produção, animais de laboratório e pelo próprio homem. O composto ptaquilosídeo encontrado na planta é considerado atualmente o principal responsável pelo aparecimento de neoplasias. No homem, existem três maneiras pelo qual este pode ser intoxicado: ingestão da planta, contato físico (inalação dos esporos ou ingestão de água contaminada) e ingestão de leite cru de animais que ingeriram a planta.

Palavras-chave: Pteridium aquilinum, samambaia, neoplasia, homem.

\begin{abstract}
The article reviews some of the main characteristics of Pteridium aquilinum (bracken fern) and the main consequences of its ingestion by livestock animals, laboratory animals and man. Ptaquiloside is considered the main responsible for the neoplasias in these cases. Three main routes may lead to human exposure to the toxic effects of bracken fern: eating the plant, physical contact (inhalation of the spores or ingestion of contaminated water) and ingestion of raw milk from affected animals.
\end{abstract}

Key words: Pteridium aquilinum, bracken fern, neoplasia, man.

\section{Introdução}

As pteridófitas compõem um grupo de plantas que existem no planeta há pelo menos 250 milhões de anos. As samambaias são o maior grupo de pteridófitas existentes no mundo atualmente (PAGE, 1976). São consideradas uma das cinco plantas mais bem sucedidas do reino vegetal (ALONSOAMELOT et al., 1993).
Estima-se a existência da samambaia (Pteridium aquilinum) desde o período quaternário, ou seja, há aproximadamente dois milhões de anos. Sua importância para as atividades humanas começou há cerca de 5000 anos na fase neolítica. Neste período, as florestas começaram a ser devastadas em decorrência do início da atividade agropecuária e de subsistência, favorecendo a disseminação e o aparecimento da Pteridium aquilinum pelo mundo.

\footnotetext{
1 Aluno do Programa de Pós Graduação (Mestrado) em Ciência Animal - CCA - UEL e-mail:guidurante@yahoo.com

2 Professora do Depto. Med. Vet. Preventiva, UEL email: anapaula@uel.br

* Autor para correspondência.
} 
Há ainda relatos de que o homem pré-histórico consumia esta planta regularmente. Além disso, na Idade Média, animais eram comumente alimentados com samambaia e as camas para cavalos e gado eram feitas com esta planta (FENWICK, 1988).

Em 1893, foi descrita uma síndrome hemorrágica no gado, que foi associada à presença de samambaia nos pastos (FENWICK, 1988). A associação de hematúria e tumores de bexiga em bovinos que ingeriam cronicamente a samambaia foi relatada apenas a partir de 1940 (HIRONO et al., 1978). No Brasil, os primeiros casos de intoxicação pela samambaia em bovinos foram descritos no início da década de cinqüenta (OLIVEIRA et al., 1998). Desde o final do século XIX, a literatura científica contém referências sobre a toxicidade da samambaia para o gado, porém somente em 1965 é que se comprovou a carcinogenicidade desta planta (EVANS et al.,1982).

A espécie Pteridium aquilinum (L.) Kunh está incluída no gênero Pteridium e na família das Polypodiaceae. O gênero Pteridium ocorre nos cinco continentes não sendo encontrado apenas nas calotas polares, em regiões de clima árido e seco ou em regiões de florestas tropicais fechadas (ALONSOAMELOT, 1999). Possui duas subespécies: aquilinum e caudatum. A subespécie aquilinum contém oito variedades e ocorre no norte da cordilheira dos Andes, América Central e do Norte, África e Eurásia. A subespécie caudatum contém quatro variedades que se restringem ao hemisfério sul, sendo encontrada em toda Australásia e grande parte da América do Sul (PAGE, 1976).

No Brasil, a subspécie caudatum ocorre em regiões montanhosas e serranas, desenvolvendo-se melhor em zonas frias, de boa pluviosidade e com solos bem drenados. A variedade arachnoideum é a única encontrada nas regiões norte do Rio Grande do Sul; Santa Catarina; Paraná; São Paulo; sul, sudeste e centro de Minas Gerais; norte do Rio de Janeiro e sudoeste do Espírito Santo. Há ainda pequenos focos no Acre, Amazonas, Mato Grosso, Pernambuco e Bahia (TOKARNIA; DOBEREINER, 2000).
A Pteridium aquilinum var. arachnoideum encontrada no Brasil, é uma planta rizomatosa, com folhas grandes, de 60 a $180 \mathrm{~cm}$ de comprimento e 60 a $120 \mathrm{~cm}$ de largura; bipinadas, com as pinas profundamente lobadas e glabras lanuginosas ferrugíneas na face dorsal. As folhas formam touceiras densas ou se estendem ao longo dos rizomas (GAVA, 1994). Normalmente o rizoma e seus rizóides, estão profundamente enterrados, o que permite à samambaia resistir às queimadas (DURÃO et al., 1995). O rizoma atua também como órgão de armazenamento de nutrientes, possuindo propriedades de expansão, o que facilita a colonização e a fixação da planta no solo (FENWICK, 1988).

As zonas geográficas onde a samambaia predomina e onde freqüentemente ocorrem as intoxicações dos bovinos têm solos pobres, ácidos, com baixos níveis de cálcio e fósforo (DURÃO et al., 1995).

A invasão da samambaia nas pastagens está relacionada com o manejo das terras, diminuindo apreciavelmente quando os campos são cultivados, sem, todavia desaparecer completamente. A sua incidência volta a aumentar quando a cultura de terra é abandonada. Relata-se que a freqüência de intoxicação pela samambaia em bovinos aumenta em regiões em que, devido à má qualidade dos solos, as culturas agrícolas foram abandonadas (DURÃO et al., 1995). O desmatamento florestal através do fogo, incentivado pelas atividades agropecuárias, minerais ou madeireiras faz com que a samambaia se propague pelo campo, afetando profundamente o ecossistema local e pondo em risco a economia da atividade agropecuária (ALONSO-AMELOT, 1999). Demonstrou-se que além da grande resistência frente a diversos ambientes, a samambaia possui uma capacidade invasiva muito alta em decorrência de seus esporos. Em épocas secas os esporos são lançados para a atmosfera podendo viajar centenas de quilômetros e colonizar outras áreas (TROTTER, 1990).

A fome é o principal fator que leva os animais a ingerirem a planta, devido à superlotação do pasto, falta de material fibroso na alimentação ou ainda 
períodos de seca (pós-inverno). Animais que são colocados no pasto contaminado após transportes prolongados, hábito em ingerir a planta e uso de feno contaminado são outras causas que podem levar a um quadro de intoxicação pela Pteridium aquilinum (GAVA, 1994). Os rizomas expostos pela aração, quando ingeridos causam intoxicações nos bovinos (TOKARNIA; DOBEREINER, 2000).

A concentração dos diversos componentes tóxicos da Pteridium aquilinum varia consideravelmente com a idade e parte da planta. $\mathrm{O}$ ápice do broto de onde irão desenvolver-se as folhas é a região que concentra a maior quantidade de substâncias mutagênicas (HIRONO et al., 1973). No rizoma também concentram-se altas quantidades do composto ptaquilosídeo (SAITO et al., 1989). Porém, em relação a esta parte da planta há resultados completamente diferentes, visto que a luminosidade e a variedade da planta podem interferir na concentração do ptaquilosídeo (SMITH et al., 1999). Ainda, o tipo de solo, o clima e a geografia interferem na toxicidade da Pteridium aquilinum, tanto entre as variedades, como em exemplares da mesma variedade (ALONSO-AMELOT, 1999). O maior nível do ptaquilosídeo no broto ocorre na a primavera declinando gradualmente próximo ao inverno (SMITH et al., 1999). As variedades caudatum e arachnoideum encontradas na América do Sul têm preferências por habitats diferentes. A variedade arachnoideum, encontrada no Brasil, prefere regiões com no mínimo $700 \mathrm{~m}$ de altitude, podendo ser encontradas em regiões de até 3000m (ALONSOAMELOT, 1999).

\section{Patogenia}

Ao longo dos anos, várias substâncias encontradas na samambaia foram relacionadas à atividade carcinogênica. Estes resultados baseiam-se principalmente em modelos experimentais em animais de laboratório. $\mathrm{O}$ tanino foi considerado uma dessas substâncias quando inoculado em ratos (WANG et al.,1976). Entretanto, outros trabalhos demonstraram que a administração de samambaia sem tanino induziu a uma alta incidência (47\%) de tumores intestinais nesta mesma espécie (PAMUCKU et al.,1969). Atualmente relaciona-se a ação do tanino à formação de um complexo com proteínas insolúveis e não digeríveis. Isto leva a um emagrecimento progressivo do animal, com perturbações na fisiologia do aparelho digestório final em ruminantes (ALONSO-AMELOT, 1999). Também são verificados sintomas nervosos como opistótono, convulsões e morte sendo a lesão uma poliencefalomalácia cerebral em eqüinos (SMITH et al.,1999). O tanino não é considerado um componente carcinogênico da Pteridium aquilinum (EVANS et al., 1982).

Em relação aos flavonóides, substâncias encontradas em diversas plantas, há controvérsias na literatura quanto a sua ação carcinogênica. A quercetina foi classificada como carcinógeno primário da samambaia por Cooper e Johnstone, (1984). Pamucku e colaboradores (1980) demonstraram que a administração de quercetina induz a formação de tumores em intestino e bexigas de ratos, porém numa porcentagem menor do que o grupo que foi submetido a uma dieta com toda samambaia. Outros estudos, entretanto, não demonstraram carcinogenicidade para esta substância em ratos, principalmente em estudos de longo prazo (MORINO et al., 1985).

Evans (1979) considerou o ácido chiquímico como o principal constituinte ativo da samambaia com atividade carcinogênica em camundongos. $\mathrm{O}$ efeito carcinogênico não foi evidenciado quando o ácido chiquímico foi administrado para bovinos e ratos (HIRONO et al., 1977).

Da ampla variedade de compostos químicos isolados da Pteridium aquilinum (prunasina, catecolaminas, ácidos succínicos e fumarínicos) considera-se atualmente que o ptaquilosídeo, um glicosídeo, é o principal carcinógeno desta planta (SANTOS et al., 1992). O ptaquilosídeo ou aquilídeo A foi isolado pela primeira vez em 1983 por Niwa e 
colaboradores, (1983) e por Van Der Hoeven e colaboradores, (1983) quase que ao mesmo tempo. A partir destes trabalhos então, várias metodologias foram desenvolvidas para isolar e purificar o ptaquilosídeo da samambaia (OELRICHS et al., 1995).

O ptaquilosídeo é um composto instável em solução aquosa na presença de ácido, base ou calor, degradando-se muito rapidamente em pterosina B e D-(+) glicose devido a eliminação da D-(+) glicose seguida por uma aromatização em soluções ácidas fracas (AGNEW; LAUREN, 1991). A pterosina B é apenas uma, de um grupo de 20 tipos de pterosinas e pterosídeos descobertos (POTTER; BAIRD, 2000). Uma característica importante é que em condições alcalinas, o ptaquilosídeo pode dar origem a um conjugado denominado dienona e conseqüentemente a formação da pterosina $\mathrm{B}$ não será tão rápida (SAITO et al., 1989). A dienona, sob condições ácidas decompõe-se em pterosina B. Os pesquisadores verificaram que o anel ciclopropil da dienona se abre e promove o aparecimento de uma terminação livre $(\mathrm{OH})$ que interage preferencialmente com um átomo de nitrogênio da base adenina do DNA. A dienona é considerada atualmente o verdadeiro componente tóxico (MATOBA et al., 1987).

A dienona é capaz de associar-se quimicamente com uma infinidade de proteínas com terminais amino expostos, como o DNA, já que o ptaquilosídeo atravessa a membrana celular e nuclear das células (ALONSO-AMELOT, 1999). No núcleo causa uma alteração permanente e irreparável em determinados genes. Estes genes são os que codificam a ativação de outros genes ou têm função reguladora de outros processos bioquímicos: como por exemplo, o gene p53 que regula a apoptose e a supressão de tumores (SANTOS et al., 1992). Deste modo, a dienona propicia a formação e multiplicação de um tecido afuncional e canceroso (ALONSO-AMELOT, 1999).

Foi descrita uma possível interação entre os carcinógenos da samambaia e o papilomavírus bovino tipo IV (JARRET et al.,1978). Sugere-se inclusive que a samambaia tem efeito imunossupressor, contribuindo para o desenvolvimento tumoral promovido por este vírus (TOKARNIA; DOBEREINNER, 2000). Verificou-se que o vírus está associado aos papilomas do trato digestório superior em animais (HIRONO et al, 1982). No entanto, a presença do vírus não é obrigatória para que haja a transformação do papiloma em carcinoma (CAMPOS et al. 1985). Segundo Wosiacki (2000) hiperplasia, hipoplasia, descamação, degeneração do epitélio e infiltrado mononuclear difuso são sugestivos de Papiloma vírus tipo 2 (BPV-2) em bexiga de bovinos.

A associação entre estes agentes ainda é controversa devido aos resultados diversos relatados. Pamucku e colaboradores (1976) observaram que a administração de samambaia a animais de laboratório isentos de papilomavírus produziu tumores. Em outro estudo, o produto amplificado pela PCR para BPV2 foi detectado em $60,42 \%$ das amostras de bexiga. Ainda, o BPV não foi detectado em nenhum dos fragmentos colhidos de bexiga sem lesão macroscópica provenientes de animais clinicamente sadios e sem acesso a samambaia (WOSIAKI, 2000). Olson e colaboradores (1965) verificaram que o papilomavírus produziu tumores na parede da bexiga de bovinos sem estes terem qualquer acesso a samambaia.

A intoxicação crônica por Pteridium aquilinum em bovinos leva ao desenvolvimento de neoplasias principalmente em faringe, esôfago e bexiga. Estes órgãos apresentam condições alcalinas, o que propicia a transformação do ptaquilosídeo em dienona. Deste modo, o pH alcalino da saliva $(8.1-8.2)$ e da urina de bovinos $(7.5-8.5)$ favorece o aparecimento de tumores na base da língua, do esôfago e da bexiga. Em monogástricos, parte do ptaquilosídeo é inativada no estômago pela formação de pterosina $\mathrm{B}$, porém, a maior parte passa sem se decompor, indo para o intestino sem que ocorra reabsorção, devido ao seu alto peso molecular e hidrofilia (MATOBA et al.,1987). A presença de ptaquilosídeo no $\mathrm{pH}$ alcalino do intestino favorece o aparecimento de neoplasias nesta região. Já as condições ácidas da bexiga em 
monogástricos não propiciam a formação de tumores pelo ptaquilosídeo (VAN DE HOEVEN et al.,1983).

\section{Intoxicação Animal}

A intoxicação aguda também chamada de síndrome hemorrágica aguda afeta bovinos jovens e adultos (EVANS; MASON, 1965). O quadro hemorrágico nos bovinos ocorre três semanas após o início da ingestão de 10 a $30 \mathrm{~g} / \mathrm{kg}$ de samambaia (TOKARNIA; DOBEREINER, 2000). A intoxicação se dá de maneira cumulativa e resulta da ingestão de broto de samambaia ou de seus rizomas num período de duas a quatro semanas (HOPKINS, 1986).

A principal alteração no gado intoxicado é a depressão da medula óssea, com severa leucopenia, especialmente dos granulócitos, trombocitopenia e síndrome hemorrágica (HIRONO et al., 1984). São descritos como sinais clínicos característicos a hiperemia e hemorragia na pele e mucosas, bem como a eliminação de coágulos pelas fezes. Lesões cutâneas como picadas de insetos ou agulhas podem resultar em hemorragias (PAMUKCU; PRICE, 1969). Outros sinais relatados são: descarga nasal, dispnéia, perda do apetite e imunossupressão com possível infecção secundária (DOBEREINER et al.,1967).

Os achados de necropsia nos bovinos consistem em hemorragias em vários órgãos e tecidos e eventualmente úlceras nas mucosas e coágulos na luz intestinal. Na histopatologia verifica-se acentuada rarefação do tecido hematopoiético da medula óssea (TOKARNIA; DOBEREINER., 2000).

Embora na literatura haja citações de intoxicação por Pteridium aquilinum nas espécies eqüina e ovina, no Brasil ainda não foi confirmada a doença nessas espécies. Gava (1994) descreveu a intoxicação natural em asininos. Anorexia e sinais neurológicos como incordenação motora, paralisia de membros anteriores e convulsões são sinais verificados em eqüinos (ALONSO-AMELOT, 1999). A diferença nos sinais clínicos apresentados entre ruminantes e monogástricos em casos de intoxicação aguda por Pteridium aquilinum é explicada pelo fato dos últimos serem dependentes de níveis adequados de vitamina $\mathrm{B}_{1}$ (tiamina) em sua dieta, ao contrário dos ruminantes que sintetizam esta pela ação da microflora ruminal. A samambaia contém tiaminase, promovendo deste modo a avitaminose $\mathrm{B}_{1}$ que causa principalmente distúrbios nervosos (HOPKINS, 1990).

Outras toxinas, como o ácido cianídrico $(\mathrm{HCN})$, estão envolvidas na intoxicação aguda em ruminantes. Na Venezuela constatou-se que a variedade arachnoideum possui um teor de $\mathrm{HCN}$ muito mais alto que o da variedade caudatum (ALONSO-AMELOT, 1999).

A intoxicação crônica leva ao aparecimento de uma síndrome denominada hematúria enzoótica bovina (HEB). Este quadro ocorre quando há ingestão da planta em uma quantidade inferior a $10 \mathrm{~g} /$ $\mathrm{kg}$ /dia durante um ou mais anos (TOKARNIA; DOBEREINER, 2000). A HEB é caracterizada por hemorragias da vesícula urinária e pela presença de tumores na parede da bexiga (PRICE; PAMUCKU, 1968). Os animais afetados apresentam a urina de coloração avermelhada e quando esta coloração não é evidenciada, microscopicamente observa-se a presença de hemáceas na urina (FENWICK, 1988). Há hematúria intermitente, prostração, anemia, emagrecimento, raras vezes incontinência urinária, sobrevindo mais tarde à morte (TOKARNIA; DOBEREINER, 2000).

$\mathrm{Na}$ maioria dos casos, aparecem vesículas altamente vascularizadas na mucosa da bexiga. Estas vesículas podem ser carcinomas que no seu processo de crescimento descontrolado acabam por derramar sangue diretamente na urina (ALONSO-AMELOT, 1999). As neoplasias não se limitam à bexiga podendo ser observadas na cavidade oral, língua, esôfago, rúmem e intestino (HOPKINS, 1990). Os processos neoplásicos que ocorrem no aparelho digestório são classificados como carcinomas epidermóides. 


\section{Intoxicação Experimental}

Em animais de laboratório a carcinogênese promovida pela samambaia é modulada pela dose, processamento da amostra e tempo de exposição. As lesões mais freqüentes são pólipos, adenocarcinomas e sarcomas no final do íleo (FENWICK, 1988). Tumores em fígado, mama e bexiga também são descritos em ratos (HIRONO et al., 1983).

Amostras brasileiras de Pteridium aquilinum não promoveram a formação de neoplasias em ratos após 32 semanas de administração de uma dose baixa de samambaia na dieta (OLIVEIRA et al., 1995). A carcinogenicidade do broto de samambaia da região de Ouro Preto - MG foi testada em ratos, através de uma dieta com 33\% de samambaia desidratada fornecida durante nove semanas. Dos 12 animais apenas um apresentou lesões neoplásicas, devido ao baixo consumo de ração (SANTOS et al., 1986). Em outro estudo, os animais receberam ração contendo $5 \%$ de broto de samambaia desidratado durante 70 semanas. O resultado foi que $100 \%$ do grupo teste apresentou neoplasias, especialmente no íleo (SANTOS et al., 1987).

A comparação entre a planta processada (cozida e tratada com cinza ou bicarbonato de sódio) e crua demonstra maior carcinogenicidade na samambaia crua. A atividade carcinogênica diminui após o processamento (HIRONO et al., 1972). O potencial tumorigênico da água de fervura do broto de samambaia também já foi verificado (HIRONO et al., 1978). Ratos de 45 dias de idade que receberam água de fervura por 54 dias desenvolveram em 95\% dos animais tumores ileais e em $45 \%$ tumores vesicais e ileais (SANTOS et al., 1992).

\section{Intoxicação Humana}

São citados três modos de intoxicação do homem pela samambaia: ingestão da planta, contato físico com os esporos (inalação ou ingestão da água) e ingestão do leite cru de animais contaminados
(POTTER; BAIRD, 2000). O consumo do broto de samambaia (warabi) é particularmente comum no Japão. Para o consumo, o broto é fervido na água com cinzas ou bicarbonato de sódio, sendo ingerido como salada (Santos et al., 1992). Este procedimento reduz, porém não elimina a carcinogenicidade do broto (HIRONO et al., 1972). No Brasil esse hábito existe em populações orientais da cidade de São Paulo e norte do Paraná. Populações não orientais também consomem o broto nas regiões de Minas Gerais e Espírito Santo. Alguns estudos demonstram correlação entre regiões infestadas por samambaia e índices elevados de câncer gástrico em seres humanos, principalmente os que vivem em áreas rurais (EVANS et al., 1986).

Estudos no Japão verificaram que o risco de câncer de esôfago é 2,1 vezes maior nos homens e 3,7 vezes maior nas mulheres que consomem o broto regularmente (POTTER; BAIRD, 2000). No Brasil, um estudo epidemiológico registrou, que há associação entre a ingestão do broto de samambaia com o câncer gástrico $(3,45 \mathrm{x})$ e com câncer de esôfago $(3,40 \mathrm{x})$ nos homens (MARLIERE et al.,1998). Também na Costa Rica, estudos comprovaram a correlação entre a hematúria enzoótica bovina e o câncer gástrico e do esôfago no homem (VILLALOBOS-SALAZAR et al., 1985).

O consumo indireto dos produtos da samambaia pode ocorrer pela ingestão do leite ou da carne (SMITH, et al., 1999). Já foi demonstrado que o leite proveniente de vacas que se alimentam regularmente de brotos de samambaia, contém ptaquilosídeo e causa câncer em roedores (EVANS et al., 1972). A concentração do ptaquilosídeo no leite corresponde a $8,5 \%$ da quantidade ingerida pelo animal (ALONSO-AMELOT et al.,1996). A associação entre a ingestão de leite de animais alimentados com broto de samambaia e o desenvolvimento de neoplasias foi comprovada experimentalmente em roedores (VILLALOBOS-SALAZAR et al., 1990).

No Reino Unido uma possível associação entre a inalação de esporos da samambaia e a presença de 
câncer, tem sido estudada em camundongos. Verificou-se inclusive o desenvolvimento de neoplasias em camundongos tratados com esporos de samambaia e alterações de DNA em tecidos do trato gastrintestinal alto. (POVEY et al., 1996). A contaminação da água por esporos de Pteridium aquilinum tem sido considerada como fonte de contaminação para o ser humano (EVANS et al., 1986).

\section{Considerações Finais}

O problema da intoxicação pela samambaia não se restringe aos animais de produção, mas apresenta um potencial em franca expansão que envolve diretamente a saúde humana. A intoxicação crônica pela Pteridium aquilinum nos animais domésticos já é de conhecimento da comunidade científica há décadas, entretanto a repercussão econômica na pecuária persiste. Sabe-se que há variações na toxicidade da planta entre localidades geográficas diferentes, mesmo esta planta sendo da mesma variedade. O tipo de solo, clima e altitude têm papel fundamental no estabelecimento dos casos de intoxicação pela samambaia. Neste sentido, ainda não há dados convincentes e concretos relacionados a este assunto no Brasil, onde a planta existe em vastas regiões. Ainda, estes estudos contribuem para esclarecer a relação entre neoplasias do aparelho digestório na população humana e o consumo direto e/ou indireto da samambaia.

\section{Referências Bibliográficas}

AGNEW, P.M.; LAUREN, D.M. Determination of ptaquiloside in bracken fern (Pteridium esculentum). $J$. Chromatography, v.538, p.462-68, 1991.

ALONSO-AMELOT, M.E.; CASTILHO,U.; DE JONGH, F. Passage of the bracken fern carcinogen ptaquiloside into bovine milk. Le Lait, v.73, p. 323-32, 1993.

ALONSO-AMELOT, M.E.; CASTILHO,U.; SMITH, B.L.; LAUREN, D.R. Bracken ptaquiloside in milk. Nature, v.382, p. $587,1996$.

ALONSO-AMELOT, M.E. Helecho macho, salud animal y salud humana. Rev. Fac. Agron. (LUZ), v.16, p.528-47, 1999.
CAMPOS, M.S.; MOOR, M.H.; SARTIRANA, M.L.; KENNEDY, I.M.; JARRET, W.F.H. The presence of bovine papillomavirus type $4 \mathrm{DNA}$ is not required for the progression to, or the maintenance of the malignant state in cancers of the alimentary canal in cattle. Journal of E.M.B.O, v.4, p.1819-25, 1985.

COOPER, M.R.; JOHNSTONE, A.W. Poisonous plants in Britain and their effects on animals and man. Ministry of agriculture, Fisheries and Food. Reference Book, $\mathrm{n}, 161,1984$.

DÖBEREINER, J.; TOKARNIA, C.H.; CANELLA, C.F.C. Occurrence of enzootic haematuria and epidermoid carcinoma of the upper digestive tract of cattle in Brazil. Pesq. Agropec. Brasil., v.2, p.489-504, 1967.

DURÃO, C.J.F.; FERREIRA, L.M.; CABRAL, A.; PELETEIRO, C.M.; AFONSO, F.; CORREIA, J. Pathological and clinical aspects of bovine enzootic hematuria. Revista Portuguesa de Ciências Veterinárias, v.XC, n.515, julho/ setembro, p. 132-137, 1995.

EVANS, I.A.; MASON, J. Carcinogenic activity of bracken. Nature (Lond), v.208, p. 913-914, 1965.

EVANS, I.A.; JONES, R.S.; MAINWARING-BURTON, R. Passage of bracken fern toxicity into milk. Nature (Lond), v.237, p. 107-108, 1972.

EVANS, I.A. Bracken carcinogenicity. Research Vet. Science, v.26, p.339-348, 1979.

EVANS, I.A; PROROK, J.H.; COLE, R.C.; AL-SALMANI, M.H.; AL-SAMARRAI, A.M.H.; PATEL, M.C.; SMITH, R.M.M. The carcinogenic, mutagenic and teratogenic toxicity of bracken. Proc. Royal Soc. Edinburgh, v.81B, p.65-77, 1982.

EVANS, I.A. The carcinogenic, mutagenic and teratogenic toxicity of bracken. In: Bracken, Ecology, Land use and Control Technology. Eds Smith R.T \& Taylor J.A. Parthenon Publishing Group, Carnforth, Lancs, 1986, p. 139-146.

FENWICK, G.R. Bracken (Pteridium aquilinum) - toxic effects and toxic constituents. Journal Sci. Food Agric., v.46, p.147-173, 1988 .

GAVA, A. Intoxicações por plantas de ação antihematopoiética e mutagênica. In: RIET-CORREA, F.; SCHILD, A.L.; MÉNDEZ, M.D.C. Doenças de Ruminantes e Equinos. Pelotas: Ed Universitária/UFPel, 1994, p. 247-258.

HIRONO, I.; SHIBUYA, C.; SHIMIZU, M.; FUSHIMI, K. Carcinogenic activity of processed bracken used as human food. J. Natl Cancer Institute, v. 48, p. 1245-1250, 1972.

HIRONO, I.; FUSHIMI, K.; MORI, H.; MIWA, T.; HAGA, M. Comparative study of carcinogenic activity in each part of bracken. J. Natl Cancer Institute, v.50, p. 13671371, 1973. 
HIRONO, I.; FUSHIMI, K.; MATSUBARA, N. Carcinogenicity test of shikimic acid in rats. Toxicol. Letters, v.1, p.9-10, 1977.

HIRONO, I.; USHIMARU, Y.; KATO, K.; MORI, H.; SASAOKA, I. Carcinogenicity of boiling water extract of bracken, Pteridium aquilinum. Gann, v.69, p.383-388, 1978.

HIRONO, I.; HOSAKA, S.; KUHARA, K. Enhancement by bracken of induction of tumours of the upper alimentary tract by N-propyl- N-nitrosourethan. Br. Journal of Cancer, v.46, p.423-427, 1982.

HIRONO, I.; AISO, S.; HOSAKA, S.; YAMAJI, T.; HAGA, $\mathrm{M}$. Induction of mammary cancer in $\mathrm{CD}$ rats fed bracken diet. Carcinogenesis, v.4, p.885-887, 1983.

HIRONO, I.; AISO, S.; YAMAJI, T.; NIWA, H.; OJIKA, M.; WAKAMATSU, K.; YAMADA, K. Hyperplastic nodules of the liver induced in rats fed bracken diet. Cancer Letters, v.22, p.151-155, 1984.

HOPKINS, A. Bracken (Pteridium aquilinum): its distribution and animal health implications. Br. Vet. Journal, v.146, p.316-326, 1990.

HOPKINS, N.C.G. Aetiology of enzootic haematuria. The Veterinary Record, june,v.28, p.715-717, 1986.

JARRET, W.F.H.; MCNEIL, P.E.; GRIMSHAW, W.T.R.; SELMAN, I.E.; MCINTYRE, W.I.M. High incidence area of cattle cancer with a possible interaction between an environmental carcinogen and papilloma virus. Nature (Lond), v.274, p.215-217, 1978.

MARLIÈRE, C.A., SANTOS, R.C., GALVÂO, M.A.M., SOARES, J.F. Ingestão de broto de samambaia e risco de câncer de esôfago e estômago na região de Ouro Preto, MG. Revista Brasileira de Cancerologia, v.44(3), p. 225229, 1998.

MATOBA, M.; SAITO, E.; SAITO, K.; KOYAMA, K.; NATORI, S.; MATSSHIMA, T.; TAKIMOTO, M. Assay of ptaquiloside, the carcinogenic principle of bracken, Pteridium aquilinum, by mutagenicity testing in Salmonella typhimurium. Mutagenesis, v.2, p.419-425, 1987.

MORINO, K.; MATSUKURA, N.; KAWASHI, T.; OHGAKI, H.; SUGIMURA, T.; HIRONO, I. Carcinogenicity test of quercetin and rutin in golden hamsters by oral administration. Carinogenesis, v.3, p.93-97, 1985.

NIWA, H.; OKIJA, M.; WAKAMATSU, K.; YAMADA, K.; HIRONO, T.; MATSUSHITA, K. Ptaquiloside, a novel norsesquiterpine glucoside from bracken, Pteridium aquilinum var. latiusculum. Tetrahedron, v.24, p.41174120, 1983.

OELRICHS, P.B.; NG, J.C.; BARTLEY, J. Purification of ptaquiloisde, a carcinogen from Pteridium aquilinum. Phytochemistry, v.40, n.1, p.53-56, 1995.
OLIVEIRA, G.P.; MATSUMOTO,T.; PRIMAVESI, A.C. Ocorrência de intoxicação causada por samambaia (Pteridium aquilinum) na região nordeste do Paraná. Comunicado Técnico-EMBRAPA, n.20,outubro, p.1-9, 1998.

OLIVEIRA, M.L.; ROCHA, N.S.; FUKUSHIMA, S.; CAMARGO, J.L. Abcence of promoting potential of bracken fern (Pteridium aquilinum) in rat urinary bladder carcinogenesis induced by N-butyl-N-(hydroxybutyl)nitrosamine and uracil. Teratogenesis, Carcinogenesis and Mutagenesis, v.15, p.191-199, 1995.

OLSON, C.; PAMACKU, A.M.; BROBST, D.F.; Papilloma virus and bracken fern. Cancer Research, v.25, p.840, 1965.

PAGE, C.N. The taxonomy and phytogeography of bracken - a review. Bot J. Linn. Soc, v.73, p.1-34, 1976.

PAMUKCU, A.M.; PRICE, J.M. Induction of intestinal and urinary bladder cancer in rats by feeding bracken fern. J.Natl.Cancer Inst., v.43, p.275-281, 1969.

PAMUKCU, A.M.; PRICE, J.M; BRYAN, G.T. Naturally occurring and bracken fern-induced bovine urinary bladder tumors. Vet. Pathol, v.13, p.110-1

PAMUCKU, A.M., YALCINER,S., HATCHER,J.F., BRYAN, J.T. Quercetin a rat intestinal and bladder carcinogen present in bracken fern (Pteridium aquilinum). Cancer Research, v.40, p. 3468-3472, 1980.

POTTER, D.M.; BAIRD, M.S. Carcinogenic effects of ptaquiloside in bracken fern and related compounds. $B r$. Journal of Cancer, v.83, n.7, p.914-920, 2000.

POVEY, A.C.; POTTER, D.; O’CONNOR, P.J. Ppostlabelling analysis of DNA adducts formed in the upper gastrointestinal tissue of mice fed bracken extract or bracken spores. Br. Journal of Cancer, v.74, p.1342, 1996.

PRICE, J.M.; PAMUCKU, A.M. The induction of neoplasms of the urinary bladder of the cow and the small intestine of the rat by feeding bracken fern. Cancer Res., v.28, p.2247-2251, 1968.

SAITO, K.; NAGAO, T.; MATOBA, M.; KOYAMA, K.; NATORI, S.; MURAKAMI, T.; SAIKI,Y. Chemical assay of ptaquiloside, the carcinogen of Pteridium aquilinum, and the distribution of related compounds in the pteridaceae. Phytochemistry, v.28, p.1605-1611, 1989.

SANTOS, R.C.; HOJO, E.S.; BRASILEIRO, F.G. Studies on the possible carcinogenicity of bracken fern (Pteridium aquilinum) from Ouro Preto, MG, Brazil. Cienc. Tecnol. Aliment, v.6, p. 93-98, 1986.

SANTOS, R.C.; HOJO, E.S.; BRASILEIRO, F.G. Induction of tumors by bracken fern (Pteridium aquilinum) from Ouro Preto, MG, Brazil. Braz. J. Med. Biol. Res., v.20, p.73$77,1987$. 
SANTOS, R.C.; BRASILEIRO, F.G.; SILVA, M.E. Tumorigenicity of boiling water extract of bracken fern (Pteridium aquilinum (L.) Kuhn). Cienc. Tecnol. Aliment, v.12, n.1, p.72-76, 1992.

SMITH,B.L.; LAUREN, D.R.; PRAKASH, A.S. Bracken Fern(Pteridium): Toxicity in animal and human health. Bracken Fern:Toxicity, biology and control. International Bracken Group Conference,p. 76-85, 1999.

TOKARNIA, C.H.; DÖBEREINER, J. Plantas de ação radiomimética. In: Plantas Tóxicas do Brasil, 2000, p.178-185.

TROTTER, W.R. Is bracken a health hazard? The Lancet, v.336, p.1563-1565, 1990.

VAN DER HOEVEN, J.C.M.; LAGERWEIJ, W.J.; POSTHUMUS, M.A.; VAN VELDHUIZEN, A.; HOLTERMAN, H.A.J. Aquilide A, a new mutagenic compound isolated from bracken fern (Pteridium aquilinum). Carcinogenesis, v.4, p.1587-1590, 1983.
VILLALOBOS-SALAZAR, J. Carcinogenicidad del Pteridium aquilinum y alta incidencia del cancer gástrico en Costa Rica. Rev.Cost.Cienc.Med., v.6, p.131-139, 1985.

VILLALOBOS-SALAZAR, J.; MENESES, A.; PASHOV, B. Carcinogenic effects in mice of milk from cows fed on bracken fern. In: Bracken biology and management, Thompson L.A. and Smith R.T (eds) AIAS Ocassional Publication, v.40, p.247-251, 1990.

WANG, C.Y.; CHIU, C.W.; PAMUCKU, A.M.; BRYAN, G.T. Identification of carcinogenic tannin isolated from bracken fern (Pteridium aquilinum) in rats. Journal. Natl. Canc. Inst., v.56, p.33-36, 1976.

WOSIACKI, S.R. Papiloma vírus bovino tipo $2 \mathrm{em}$ bexiga de bovinos na hematúria enzoótica; detecção utilizando a reação em cadeia pela polimerase e estudo histopatológico. Dissertação (Mestrado), CCA, Universidade Estadual de Londrina, 2000. 
